\title{
Field-scale leaching of arsenic, chromium and copper from weathered treated wood
}

ARTICLE in ENVIRONMENTAL POLLUTION · MAY 2010

Impact Factor: 3.9· DOI: 10.1016/j.envpol.2009.12.027 · Source: PubMed

CITATIONS

23
DOWNLOADS

97
VIEWS

162

6 AUTHORS, INCLUDING:

Helena M Solo-Gabriele

University of Miami

138 PUBLICATIONS 2,894 CITATIONS

SEE PROFILE

Timothy G. Townsend

University of Florida

153 PUBLICATIONS 2,495 CITATIONS

SEE PROFILE
Yong Cai

Florida International University

76 PUBLICATIONS 1,513 CITATIONS

SEE PROFILE 


\title{
FIELD-SCALE LEACHING OF ARSENIC, CHROMIUM AND COPPER FROM WEATHERED TREATED WOOD
}

\author{
A. Rasem Hasan ${ }^{\mathrm{a}}$, Ligang Hub ${ }^{\mathrm{b}}$, Helena M. Solo-Gabriele ${ }^{*}, \mathrm{a}$, Lynne Fieberc, ${ }^{\mathrm{C}}$, Yong Cai ${ }^{\mathrm{b}, \mathrm{d}}$, and \\ Timothy G. Townsend ${ }^{e}$ \\ aDepartment of Civil, Architectural and Environmental Engineering, University of Miami, 1251 \\ Memorial Dr., Coral Gables, Florida, 33124, USA \\ ${ }^{b}$ Department of Chemistry \& Biochemistry, Florida International University, 11200 SW 8th Street, \\ University Park, Miami, Florida, 33199, USA \\ 'Division of Marine Biology and Fisheries, Rosenstiel School of Marine \& Atmospheric Science, \\ University of Miami, 4600 Rickenbacker Causeway, Miami, Florida, 33149-1098, USA \\ dSoutheast Environmental Research Center, Florida International University, $11200 \mathrm{SW} 8^{\text {th }}$ Street, \\ University Park, Miami, Florida, 33199, USA \\ eDepartment of Environmental Engineering Sciences, University of Florida, 217 A.P. Black Hall, \\ Gainesville, Florida, 32611-6450, USA
}

\begin{abstract}
Earlier studies documented the loss of wood preservatives from new wood. The objective of this study was to evaluate losses from weathered treated wood under field conditions by collecting rainfall leachate from 5 different wood types, all with a surface area of $0.21 \mathrm{~m}^{2}$. Wood samples included weathered chromate copper arsenate (CCA) treated wood at low $\left(2.7 \mathrm{~kg} / \mathrm{m}^{3}\right)$, medium $\left(4.8 \mathrm{~kg} / \mathrm{m}^{3}\right)$ and high $\left(35.4 \mathrm{~kg} / \mathrm{m}^{3}\right)$ retention levels, new alkaline copper quat (ACQ) treated wood $\left(1.1 \mathrm{~kg} / \mathrm{m}^{3}\right.$ as $\mathrm{CuO})$ and new untreated wood. Arsenic was found to leach at a higher rate $(100 \mathrm{mg}$ in 1 year for low retention) than chromium and copper $(<40 \mathrm{mg})$ in all CCA treated wood samples. Copper leached at the highest rate from the ACQ sample $(670 \mathrm{mg})$. Overall results suggest that metals' leaching is a continuous process driven by rainfall, and that the mechanism of release from the wood matrix changes as wood weathers.
\end{abstract}

\section{Keywords}

ACQ; arsenic; CCA; chromium; copper; treated wood; weathered wood

\footnotetext{
(C) 2009 Elsevier Ltd. All rights reserved.

*Corresponding Author tel. 305-284-2908; fax: 305-284-2885, hmsolo@miami.edu (H. M. Solo-Gabriele).
}

Publisher's Disclaimer: This is a PDF file of an unedited manuscript that has been accepted for publication. As a service to our customers we are providing this early version of the manuscript. The manuscript will undergo copyediting, typesetting, and review of the resulting proof before it is published in its final citable form. Please note that during the production process errors may be discovered which could affect the content, and all legal disclaimers that apply to the journal pertain.

Supporting Information

Figures and tables to support experimental design and results. This material is available via the internet at http://www.sciencedirect.com 


\section{Introduction}

Chromated copper arsenate (CCA) treated wood has been phased out from most residential applications in the U.S. as of 2004. However, large amounts of treated wood products are still in service due to continued use for non-residential applications and their prolonged service life that extends from 10 years to 40 years depending on its intended use and the retention level of treatment (Alderman et al., 2003; Cooper, 1993; McQueen and Stevens, 1998). As a result, leaching of metals from CCA treated wood continues to be a concern through the slow release of the metals during the weathering process. The alternatives to CCA in the U.S. (e.g. alkaline copper quat, $\mathrm{ACQ}$ ), are wood preservative formulations that contain $\mathrm{Cu}$, and in the case of ACQ, contain another active ingredient of quaternary ammonium compounds such as DDAC (didecyldimethyl ammonium chloride or carbonate compounds).

Both CCA and ACQ treated wood are produced in set ratios of As, $\mathrm{Cr}$ and $\mathrm{Cu}$ for CCA and $\mathrm{Cu}$ and quat for ACQ. Three types of CCA have been produced over time with type $\mathrm{C}$ (47.5\% as $\mathrm{CrO}_{3}, 18.5 \%$ as $\mathrm{CuO}$, and $34 \%$ as $\mathrm{As}_{2} \mathrm{O}_{5}$ ) as the most common formulation used for products manufactured today. The most common formulation of ACQ contains $66.7 \% \mathrm{CuO}$ and $33.3 \%$ quat (AWPA, 2008). The amount of chemical added, or retention level for both CCA and ACQ treated wood, is dependent upon the intended use of the wood. The lowest retention level of CCA treated wood $\left(4 \mathrm{~kg} / \mathrm{m}^{3}\right.$; kilograms of CCA chemical on an oxide basis per cubic meter of wood) is intended for wood used in above ground applications; the highest retention level of $40 \mathrm{~kg} / \mathrm{m}^{3}$ is intended for wood submerged in marine environments (AWPA, 2008). At the lowest retention level of CCA, the amount of $\mathrm{As}, \mathrm{Cr}$ and $\mathrm{Cu}$ within the wood (in $\mathrm{g}$ of metal per kg of wood) are 1.7, 1.9, and 1.2, respectively, with concentrations increasing by a factor of 10 at the highest retention level (Jacobi et al., 2007; Khan et al., 2006a). Copper

concentrations (in $\mathrm{g}$ of $\mathrm{Cu}$ per $\mathrm{kg}$ of wood) in ACQ correspond to 3.28 at the lowest retention level $\left(4 \mathrm{~kg} / \mathrm{m}^{3}\right)$ and $13.3 \mathrm{~g} / \mathrm{kg}$ at the highest retention level $\left(16 \mathrm{~kg} / \mathrm{m}^{3}\right)$.

Concerns about the safety and environmental impact of wood preservatives have increased in recent years. Arsenic and chromium are considered human carcinogens and $\mathrm{Cu}$ can be toxic to aquatic organisms (Flemming and Trevors, 1989; Weis and Weis 1999; Dubey et al., 2007). Metals release from treated wood has been reported by many researchers during the wood service life (Khan et al., 2006a; Shibata et al., 2007), during disposal (Khan et al., 2006b; Jambeck et al., 2006; Moghaddam and Mulligan, 2007) and from recycled forms such as mulch (Jacobi et al., 2007; Shibata et al., 2006). Shibata et al. 2007 summarized other researchers' results of bulk metal loss rates ranging from an average $25 \%$ lost after 20 to 43 years of exposure in temperate Sweden (Evans and Edlund, 1993) and 22\% after 44 months in tropical Hawaii (Jin et al., 1992) and 5\% in 1 year in southern Florida (Khan et al., 2006a). Few studies document loss rates on a year to year basis and all of these studies evaluated new wood. For these studies, roughly $5 \%$ of As was shown to leach from the wood in 1 year (Kennedy and Collins, 2001; Khan et al., 2006a). No studies exist on yearly leaching rates for weathered wood. The contribution of weathering to release of CCA-components from treated wood is largely unknown, but there is substantial information available on the mechanisms of surface degradation (Lebow et al., 2003, Williams et al., 2001) to suggest that leaching rates may change as a function of weathering. Leaching rates are important in assessing the potential impacts of existing wood structures constructed prior to the phase-out of CCA-treated wood for residential purposes. Townsend et al. (2005) studied the leaching of naturally weathered treated wood using laboratory batch tests such as the Toxicity Characteristic Leaching Procedure (TCLP), Synthetic Precipitation Leaching Procedure (SPLP) and Waste Extraction Test (WET). These studies showed that the toxicity characteristic threshold of As (5 mg/l) was exceeded in most of their experiments. Khan et al. (2004) also used the TCLP and SPLP to compare As leaching from new and weathered wood and found that weathered wood leached more As and they attributed the greater leaching to natural chemical and biological 
transformations during the weathering process. Thus batch leaching tests conducted in the laboratory suggest that the weathering process increases leaching rates, but this is yet to be shown under natural field conditions.

The objectives of the current study were to evaluate leaching rates from weathered CCA-treated wood. Experiments were designed to evaluate the impacts of different retention levels of CCA and to compare leaching rates of weathered CCA-treated wood to leaching of new ACQ-treated and untreated wood. In an effort to evaluate the potential impacts of aging on leaching rates, results from the current study using weathered wood samples were compared to results from earlier studies, which utilized new CCA-treated wood.

\section{Experimental Methods}

\subsection{Rainfall leachate collection system}

Six separate leaching systems were constructed and set up outdoors within an open area located at the University of Miami, Coral Gables, FL, USA (Fig. 1). Each system was composed of an uncovered tank (Heavy Duty Polyethylene, US Plastic type Tamco® 6325, Lima, OH, USA) with interior dimensions of $91.4 \mathrm{~cm} \times 61.0 \mathrm{~cm}$ open area and $76.2 \mathrm{~cm}$ high. Each tank was supported on an aluminum frame base with an average height of $0.6 \mathrm{~m}$ from the ground and horizontal inclination of $5^{\circ}$. Rainfall leachate was captured in the tank and flowed by gravity via tubing $(12.5 \mathrm{~mm}$ in diameter) to a $70 \mathrm{~L}$ covered reservoir. The reservoir was scaled in units of $1 \mathrm{~L}$ and was covered in dark plastic to minimize the impacts of evaporation and UV light. Each wood sample placed within the tank was supported by a frame made of PVC. A plastic screen of $2 \mathrm{~mm}$ mesh size was placed below the wood samples to prevent vegetative debris from accumulating in the bottom of the tank. Rainfall depth and rainfall samples were collected from a standard rain gauge made from Plexiglas. A correlation relation was established between rainfall depth $(\mathrm{cm})$ and volume collected in tanks in order to calculate the volume in the tanks whenever they overflowed due to large rainfall events.

\subsection{Wood samples' characteristics}

Six different types of Southern Yellow Pine wood samples were used for the study (Table 1); the surface area exposed to rainfall (about $2100 \mathrm{~cm}^{2}$ ) was consistent between samples and corresponded to a ratio of 5:2 (total rainfall capture area relative to the wood surface area). One sample consisted of two new untreated boards (UW) and a second sample consisted of three new ACQ treated boards (ACQ). Both of these samples were purchased from a retail store in Miami, FL, USA. The remaining four samples were weathered CCA-treated wood samples and included replicates of low CCA-concentration treated wood boards (La-CCA and $\mathrm{Lb}-\mathrm{CCA}$ ) consisting of three boards each, medium concentration treated wood posts (M-CCA) consisting of four boards, and a high retention level (H-CCA) marine piling. Low and medium weathered wood pieces were obtained from the above ground portion of a residential fence that was 14 years of age at the time of this study. This fence was never painted but sealed twice with a clear water sealant. The weathered marine piling was manufactured in 1982 according to the date stamp on the piling and was thus 25 years old at the time of the initiation of this experiment; during its service life this piece was installed vertically, and was never submerged in marine water as it corresponded to the upper portion of the marine piling located above a deck. All wood samples in this study were sealed along the cut-edges to minimize end-effects on leaching rates.

Initial concentrations of $\mathrm{As}, \mathrm{Cr}$ and $\mathrm{Cu}$ in wood, and consequently retention levels, $\mathrm{R}_{\mathrm{x}}$, (Table 2 ), were determined by analyzing the sawdust produced during cutting wood pieces, through its entire cross-section, to the specified dimensions, except for the marine piling, where sawdust was collected from 40 holes drilled to $1.5 \mathrm{~cm}$ distributed equally on the outer surface of the 
piling. Drill holes were filled with wood sealant to minimize the effects of these holes on leaching. Sawdust samples were digested according to the U.S. EPA method 3050B (U.S. EPA, 1996), and the concentration of $\mathrm{As}, \mathrm{Cr}$, and $\mathrm{Cu}$ were measured by graphite furnace atomic absorption spectrometry (GFAAS, Model AAnalyst-600, Perkin Elmir, Shelton, CT, USA).

Total amounts of each of the three elements within each sample were calculated for each wood type as a product of each elemental concentration in wood sample times the mass of the wood, except for the mass of H-CCA, where the mass used corresponded to the volume of wood providing a CCA-depth of penetration equal half the piling diameter, as visual inspection showed that the CCA chemical did not penetrate the entire cross section.

\subsection{Water sampling and analyses}

Water samples were collected from each of the six leaching systems and the rain gauge on a weekly basis for one year starting on April 11, 2007. The first week of sampling (April 18) was carried out before the installation of wood pieces to obtain background concentrations of the systems without the wood and data showed no measurable contribution of $\mathrm{As}, \mathrm{Cr}$ and $\mathrm{Cu}$ prior to wood installation. Immediately upon collection, water samples were analyzed for $\mathrm{pH}$ (Model 525A, Orion Research Inc., Beverly, MA, USA). Samples for As, $\mathrm{Cr}$ and $\mathrm{Cu}$ were collected in high density polyethylene bottles pre-washed with acid. Those samples were filtered through $0.45 \mu \mathrm{m}$ pore-size membranes before analysis, and metal concentrations for each metal within the water samples were determined either by inductively coupled plasma mass spectrometry (ICP-MS, Elan DRCe, Perkin Elmer, Shelton, CT, USA) or by GFAAS using the same instrument listed earlier in the current paper. Detection limits by ICP-MS were $0.12,0.1$ and $0.1 \mu \mathrm{g} / \mathrm{l}$ for $\mathrm{As}, \mathrm{Cr}$ and $\mathrm{Cu}$, respectively, and by GFAAS were 3.3, 3.3 and 3.8 $\mu \mathrm{g} / \mathrm{l}$ for $\mathrm{As}, \mathrm{Cr}$ and $\mathrm{Cu}$, respectively. For computation purposes, samples below the detection limit were set at the detection limit.

\subsection{Analysis of data}

Mass losses of metals were computed as the product of the measured concentration and the volume of water within the reservoir at time of collection. Mass of CCA leached was computed by converting metal mass to its corresponding oxide as given in the CCA solution (e.g. As to $\mathrm{As}_{2} \mathrm{O}_{5}, \mathrm{Cr}$ to $\mathrm{CrO}_{3}$, and $\mathrm{Cu}$ to $\mathrm{CuO}$ ). Percentage of mass leached was computed for each metal as the percentage ratio of total leached metal over the experimental period to the initial mass retention of the metal in the wood samples. The percentage of CCA leached was evaluated in the same way, as the sum of leached metal oxides to the initial retention of CCA.

To compare with results from other studies, percentage leached and total mass leached were normalized. Percentage leached was divided by an equivalent depth equal to the volume divided by the surface area. This normalization was conducted as chemicals are believed to migrate by unidirectional diffusion in wood upon leaching from the surface. The total mass that leached during the one year study was normalized by dividing by the surface area. Units of normalized quantities were reported as $\% /(\mathrm{cm} \bullet \mathrm{yr})$ and $\mathrm{mg} /\left(\mathrm{d} \bullet \mathrm{m}^{2}\right)$. Although normalization helps to facilitate comparisons with other studies, there is inherent variability within normalized data sets that can be attributed to wood species, type of treatment process, shape of wood, and so on. As such, the normalization provided here provides an initial assessment of potential differences or similarities between weathered utilized in the current study and new treated wood used in prior studies; however it does not provide a global assessment of whether this difference is due solely to the weathering process.

Correlation $p$ and $\mathrm{R}_{2}$ values were evaluated by Pearson method. Significant differences between available data sets were evaluated by one way ANOVA on ranks using the Tukey test at $p$ values less than 0.05 . 


\section{Results and Discussion}

\subsection{Rainfall and $\mathrm{pH}$}

A cumulative amount of $176 \mathrm{~cm}$ of rainfall was measured during the sampling period; $136 \mathrm{~cm}$ was captured during the wet summer season (end of April up to end of October) and $40 \mathrm{~cm}$ captured during the following six months (dry season). In general rainfall leachate samples were mostly in the acidic range $(\mathrm{pH}<7)$ with the $\mathrm{pH}$ of the leached water higher than that of the background levels of rain and inversely proportional to the volume of leachated water $\left(\mathrm{R}^{2}\right.$ of $\left.0.42-0.5\right)$, supporting that wood buffers the $\mathrm{pH}$ of the rainwater (Shibata et al., 2007).

\subsection{Concentrations of leached metals}

Metal concentrations in the rainfall and in the leachate from the UW and ACQ samples were mostly below or around the detection limits (except for $\mathrm{Cu}$ from the ACQ). The average As, $\mathrm{Cr}$, and $\mathrm{Cu}$ concentrations measured in the rainfall and in the leachate from the UW and ACQ samples were on the order of a few micrograms per liter with the exception of $\mathrm{Cu}$ for ACQ which measured at $640 \mu \mathrm{g} / \mathrm{l}$, on average. Leachate concentrations of $\mathrm{As}, \mathrm{Cr}$ and $\mathrm{Cu}$ from the four CCA-treated wood samples oscillated over time between minimum and maximum values (Fig. SI-1) which were significantly different $(p<0.001)$ between retention levels and from levels observed in rainfall, and in leachate from UW. Also, CCA-leachate concentrations had averages that were proportional with their retention level in the wood samples (Table 3). The average measured concentration in the leachate collected from the La-CCA and Lb-CCA were approximately $100 \mu \mathrm{g} / \mathrm{l}$ for As and approximately $30 \mu \mathrm{g} / \mathrm{l}$ for $\mathrm{Cr}$ and $\mathrm{Cu}$, while for M-CCA, As measured at approx. $900 \mu \mathrm{g} / \mathrm{l}$, with $\mathrm{Cr}$ and $\mathrm{Cu}$ measuring at about an order of magnitude less ( 90 and $65 \mu \mathrm{g} / \mathrm{l}$, on average, respectively). The metal concentrations in the leachates from the H-CCA sample were the highest (As - $2000 \mu \mathrm{g} / \mathrm{l}, \mathrm{Cr}-400 \mu \mathrm{g} / \mathrm{l}$ and $\mathrm{Cu}-400 \mu \mathrm{g} / \mathrm{l}$, on average). In all cases As leached the most with the average concentration of As $3-4$ times higher than that of $\mathrm{Cr}$ and $\mathrm{Cu}$ from the L-CCA samples, $5-6$ times higher for the H-CCA sample, and $11-14$ times higher for the M-CCA sample. The replicates, La- and Lb-CCA, had similar leaching trends and bounds (Fig. SI-1) with no significant differences between these replicates whose coefficients of variation (calculated for each metal as the ratio of the standard deviation of the difference between $\mathrm{La}$ and $\mathrm{Lb}-\mathrm{CCA}$ to the mean of both $\mathrm{La}$ and LbCCA weekly concentrations) measured at 21,15 , and $18 \%$ for $\mathrm{As}, \mathrm{Cr}$ and $\mathrm{Cu}$, respectively, which support the similar behavior of metals leaching among wood pieces of same original retention, age, and use.

The $\mathrm{Cu}$ concentrations in the leachates from the ACQ sample averaged $640 \mu \mathrm{g} / \mathrm{l}$ and were high in comparison to the leachates from the CCA samples $(65 \mu \mathrm{g} / \mathrm{l}$ for the M-CCA sample and 410 $\mu \mathrm{g} / \mathrm{l}$ for the H-CCA sample). This is significant especially considering that the M-CCA sample contained twice, and $\mathrm{H}-\mathrm{CCA}$ contained 23 times the $\mathrm{Cu}$ mass of the ACQ sample. An apparent wash off effect was observed from the ACQ sample, with higher leaching levels observed during the first three months $(900 \mu \mathrm{g} / \mathrm{l})$ relative to those observed later $(530 \mu \mathrm{g} / \mathrm{l})$. This trend is consistent with studies that focused on leaching from new treated wood (Khan et al., 2004; Dubey et al., 2005).

Results also showed no strong relationship between rainfall depth and metal concentration in the leachates when considering the data on a week-by-week basis (Fig. 2 for M-CCA and ACQ). However, when data were combined into seasonal categories (wet versus dry seasons) distinct differences were observed. In general, higher average concentration of leached $\mathrm{Cr}$ observed in the wet season relative to the dry season; this difference was more pronounced at higher retention levels from the CCA treated samples (Fig. 3). Arsenic and $\mathrm{Cu}$ behaved differently. For the low retention level samples, average concentrations of $\mathrm{As}$ and $\mathrm{Cu}$ were higher during the dry season. As retention levels increase, average concentrations of arsenic 
were then higher during the wet season followed by the same shift of $\mathrm{Cu}$ just at the highest retention level. For example, the average metal concentrations for the H-CCA samples were consistently higher during the wet season in comparison to the dry season $(23,43$ and $31 \%$ greater for $\mathrm{As}, \mathrm{Cr}$ and $\mathrm{Cu}$, respectively). M-CCA followed the same trend as H-CCA for As and $\mathrm{Cr}$ with $17 \%$ and $36 \%$ increases in concentration from the wet to dry season; the average $\mathrm{Cu}$ concentration from M-CCA decreased from the wet to dry season by $13 \%$. In contrast, $\mathrm{Cr}$ concentration from L-CCA showed an increasing trend from wet to dry seasons ( $29 \%$ increase), while the As and $\mathrm{Cu}$ concentrations from L-CCA showed a decreasing trend from wet to dry season (13\% and 37\%, respectively) (Fig. 3). The ACQ sample was observed to exhibit higher average $\mathrm{Cu}$ concentration during the wet season relative to the dry season (Fig. 3). Apparently, the manner in which As and $\mathrm{Cu}$ leach changes as the retention level of metals in the wood decreases. When metals are in abundance, high rainfall promotes the transport of metals to the surface of the wood allowing for a large loss of metals during subsequent rainfall events. When metal retention levels are lower such as in L-CCA, metal transport to the wood's surface by high rainfall may be limited, resulting in a dilution effect within the collected rainfall leachate. Chromium leaching from treated wood is believed to be more responsive to prevailing moisture conditions relative to $\mathrm{As}$ and $\mathrm{Cu}$ at the different retention levels of chemicals.

\subsection{Masses of leached metals}

For a given sample, the mass of metals leached (the product of rainfall volume and concentration of metal in the leachate) was primarily dependent on rainfall volume with increases in metal mass leached as rainfall volume increased ( $p \pi .001)$. Concentration of metals in the leachate played a secondary role in influencing the mass of metals leached $(p<0.0014$ for H-CCA, $p<0.033$ for ACQ, and not significant for other wood samples). The correlation between metals' mass leached and rainfall was higher with higher CCA-retention $\left(\mathrm{R}^{2}: 0.7-0.8\right.$ for L-CCA, $0.80-0.82$ for M-CCA and $0.88-0.92$ for H-CCA). The higher leaching of metal masses from wood associated with larger collected volumes of leachate may have also been facilitated by a slight shift of the leachate $\mathrm{pH}$ towards the acidic range with larger rainfall volumes, in a fashion similar to that reported by Taylor and Cooper (2005). Although leached metals were reduced with increasing $\mathrm{pH}$ value, the correlation between these factors was not significant.

The masses of leached metals were significantly dependent on the original retention levels of wood $(p<0.001)$. The H-CCA leached As, $\mathrm{Cr}$ and $\mathrm{Cu}(2386,548$ and $418 \mathrm{mg}$, respectively over the experimental period) more than 20 times higher than L-CCA $(99.3 \pm 8.10,27.4 \pm 0.64$ and $19.9 \pm 1.6 \mathrm{mg}$, respectively), while M-CCA leached As, $\mathrm{Cr}$ and $\mathrm{Cu}(880,87.8$ and $44.2 \mathrm{mg}$, respectively) 8 times more As and $2-3$ times more $\mathrm{Cr}$ and $\mathrm{Cu}$ relative to L-CCA (Table 3). Masses of metals leached during the wet season were higher than during the dry season (Fig. 4). Roughly 70 to $80 \%$ more metals were leached during the wet season from the CCA wood samples in comparison to the dry season. For the ACQ sample, $84 \%$ more $\mathrm{Cu}$ leached during the wet season in comparison to the dry season.

Leaching of As and $\mathrm{Cu}$ was significantly correlated with the amount of $\mathrm{Cr}$ leached for all CCAtreated wood samples $\left(p<0.001 ; \mathrm{R}^{2}: 0.8-0.95\right)$. Chromium compounds act as fixing agents for both $\mathrm{As}$ and $\mathrm{Cu}$ in CCA treated wood. Loss of $\mathrm{Cr}$ from the wood may have led to higher loss of As and moderate loss of $\mathrm{Cu}$. According to manufacturer requirements, the $\mathrm{As} / \mathrm{Cr}$ and the $\mathrm{Cu} / \mathrm{Cr}$ ratios in new wood should have been at 0.89 and 0.63 , respectively. This manufacturer ratio is in contrast to the ratios observed in the leachate for all CCA samples. For all CCA samples, the As to $\mathrm{Cr}$ mass ratios was always higher than 5, while the $\mathrm{Cu}$ to $\mathrm{Cr}$ mass ratios oscillated around 1.

The mass ratios of $\mathrm{Cu}$ to $\mathrm{Cr}$ in the wood fiber were $0.67,0.59$ and 0.50 for the L-CCA, M-CCA and H-CCA, respectively, which was near the expected ratio of 0.63 ; however, the mass ratios 
of As to $\mathrm{Cr}$ in the wood fiber for L-CCA, M-CCA and H-CCA was measured at 0.28, 0.54 and 1.43 , suggesting a preferential depletion of As relative to $\mathrm{Cr}$ at the different retention levels. The difference in metals ratios between these samples may be due to the different retention levels of the original samples. The L-CCA and M-CCA samples were of lower retention level and their As/Cr ratios were generally lower whereas the H-CCA sample was characterized by an exceptionally high retention level. In order to see changes in As/Cr ratios in the H-CCA samples, a large amount of metals need to leach and perhaps the fraction leached to date ( 25 years) was not a significant fraction of the amount originally contained in the wood, whereas the amount leached from the L-CCA and M-CCA samples was significant relative to the original retention level allowing for a significant reduction of the As level in the wood fiber relative to $\mathrm{Cr}$. After one year of experimentation, the As to $\mathrm{Cr}$ ratios in the CCA-wood samples were reduced due to the higher loss of As relative to $\mathrm{Cr}$, and evaluated as $0.25,0.50$ and 1.42, for L-CCA, M-CCA and H-CCA, respectively.

The new ACQ wood sample had very low As and Cr contents as expected and the amount of $\mathrm{Cu}$ leached was $672 \mathrm{mg}$ over the experimental period. $\mathrm{Cu}$ leached from the ACQ wood sample 1.6 times and 15 times more relative to the $\mathrm{Cu}$ leached from the H-CCA and M-CCA samples.).

\subsection{Cumulative masses of metals leached}

Cumulative leaching data (Fig. 5 for the M-CCA) showed that As leached the highest when compared to $\mathrm{Cr}$ and $\mathrm{Cu}$. The cumulative mass of leached metals from all samples evaluated is highly correlated $(p<0.001)$ to the cumulative rainfall $\left(\mathrm{R}^{2}: 0.94-0.99\right)$. In general, initial leaching was low for the first month of the experiments (except for ACQ, Fig. 5) and followed by several sudden increases. These sudden increases did not occur during major rainfall events but rather occurred during weeks of low to moderate rainfall depths that follow major rainfall peaks. According to Taylor and Cooper (2005) large rainfall events (in terms of duration or intensity) lead to a deeper water-penetration level of wood where solubilisation of metals occurs. After the rainfall period, metals diffusively migrate to the surface of the wood, precipitate as water evaporates from the wood, and become available for the next rainfall period to achieve a jump in the cumulative mass leaching curve. The sudden increases observed in mass leached are consistent with the explanation provided by Taylor and Cooper (2005) and suggest that leaching of metals from preservative treated wood is a dynamic process, which involves continual solubilisation of metals. This process provides an over-abundance of metals at the wood's surface, especially when the wood is new and contains high metal retention levels.

\subsection{Metals' leaching percentages and rates}

Annual CCA leaching percentages measured in this study ran ged from $1.5 \% / \mathrm{cm}$ for the LCCA samples to $0.02 \% / \mathrm{cm}$ for the H-CCA sample. On a total mass basis, these corresponding rates resulted in $3 \mathrm{mg} / \mathrm{d}$ of CCA leached per square meter of the L-CCA sample relative to 57 $\mathrm{mg} / \mathrm{d}$ of CCA leached per square meter of H-CCA (Table 4). Consistencies were observed when comparing these levels with the yearly values published in the literature for new CCAtreated wood. In this study, the percentage of metals' masses leached was inversely proportional to the retention level of the CCA-treated wood samples, which was consistent with the results of Taylor and Cooper (2005). The lowest retention of weathered wood (L-CCA characterized by a retention level, $\mathrm{R}_{\mathrm{x}}$ of $2.69 \mathrm{~kg} / \mathrm{m}^{3}$ ) leached $6.3 \% / \mathrm{cm}$ of the As during one year, which was more than two times the amount reported by Khan et al. (2006a) for leaching of new wood, and similarly almost two to four times of the As loss from new wood as reported by Shibata et al. (2007), who reported 3.5\%/cm after 1 year, $1.5 \% / \mathrm{cm}$ during year 2 and $1.5 \% /$ $\mathrm{cm}$ during year $3\left(\mathrm{R}_{\mathrm{x}}\right.$ of samples used in these studies were $\left.3.5 \mathrm{~kg} / \mathrm{m}^{3}\right)$. All three of these studies were conducted at the same location at the campus of the University of Miami, with no significant difference in rainfall. Thus, the results from this study suggest that the As leaching 
percentages for weathered wood evaluated in the current study were roughly double that of new wood at the lower retention levels. For the medium retention, As leached at a rate of $0.8 \%$ / $\mathrm{cm}$ from M-CCA $\left(\mathrm{R}_{\mathrm{X}}\right.$ of $\left.4.79 \mathrm{~kg} / \mathrm{m}^{3}\right)$, which was similar to the rate observed for the new wood evaluated by Taylor and Cooper (2005) $\left(0.7 \% / \mathrm{cm}\right.$ for $\mathrm{R}_{\mathrm{X}}$ of $\left.5.52 \mathrm{~kg} / \mathrm{m}^{3}\right)$. Of note the rainfall depth in the Taylor and Cooper (2005) study was about $1 / 3$ of the amount measured in the current study and so differences were not observable due to the differences in weather conditions in the comparative studies.

Chromium percentage leaching as measured by Kennedy and Collins (2001) was at $0.5 \% / \mathrm{cm}$ for one year whereas Shibata et al. (2007) also measured $0.5 \% / \mathrm{cm}$ during the first year and then $0.1 \% / \mathrm{cm}$ during the second and third years of their study. The percentage leached during these other studies was comparable to the $\mathrm{Cr}$ leaching rate measured in the low retention level wood in the current study $(0.48 \% / \mathrm{cm})$. Copper percentage leaching in the current study also measured at near $0.5 \% / \mathrm{cm}$ for the lower retention (similar to Kennedy and Collins, 2001) and decreased with higher retention levels. The decrease in percentage leached with increasing retention level was consistent with observations of Taylor and Cooper (2005).

In the current study, the annual amount of As mass leached for L-CCA, M-CCA, and H-CCA was 99, 880, and $2386 \mathrm{mg}$, respectively. The total masses leached when averaged on a daily basis show an As loss rate of 1.3, 11.5 and $31 \mathrm{mg} / \mathrm{d}$ per square meter of horizontal surface area for the low, medium and the high retention levels (Table 4), showing an increasing trend for the mass leached with increasing retention levels. The As mass leached from the L-CCA samples were comparable with those measured by Shibata et al. (2007), Khan et al. (2006a) and Kennedy and Collins (2001). Despite, the increase in percentage leaching as wood weathers, As mass leached was slightly higher for the studies which evaluated new wood. The explanation for these trends is twofold. First, new wood has higher metals' retention, and a significant wash-off effect is observed for new wood when it is first put into service. Thus new wood releases a larger mass when first put into service because of the greater amount of metals in the wood and the release of metals that have accumulated. Second, new wood has a larger retention of metals in the wood. The larger retention results in a greater amount of metal mass in the wood fiber (divisor), which contributes to the lower percent leaching for new wood relative to weathered wood. Mass leaching of $\mathrm{Cr}$ appears to be similar between the weathered wood in the current study and new wood from prior studies. . Shibata et al. (2007) documents that chromium leached at a rated of $0.45 \mathrm{mg} /\left(\mathrm{d} \cdot \mathrm{m}^{2}\right)$ from new wood in their study whereas 0.36 $\mathrm{mg} /\left(\mathrm{d} \cdot \mathrm{m}^{2}\right)$ was observed from the weathered (low retention) in the current study. Chromium leaching rates were not as easily comparable to the results from Taylor and Cooper (2005), due to the difference in the field environment and rainfall depths of both experimental locations. Copper mass leached from weathered wood in the current study was comparable to that observed by Kennedy and Collins (2001) for new wood and the yearly mass loss observed in the current study were lower than those observed by Taylor and Cooper (2005).

The total amount of $\mathrm{Cu}$ lost from the ACQ-treated wood sample was the highest $(2.5 \% / \mathrm{cm})$ among all wood pieces in the experiment. This was observed regardless of the fact that the ACQ sample was characterized by half the wood volume and contained half the amount of $\mathrm{Cu}$ of the M-CCA sample. The mass loss of $\mathrm{Cu}$ from the ACQ was very high $\left(8.77 \mathrm{mg} /\left(\mathrm{d} \cdot \mathrm{m}^{2}\right)\right)$. Dubey (2005) also observed that $\mathrm{Cu}$ leached from new ACQ wood at a rate seven times higher than the rate from new CCA. Similar results have been reported by Stook et al. $(2004 ; 2005)$ for batch leaching experiments. This result suggests that $\mathrm{Cu}$ is not as strongly fixed in ACQtreated wood in comparison to CCA-treated wood, thus potentially resulting in shorter service lives of wood products treated with this $\mathrm{Cu}$-based alternative. 


\section{Conclusions}

The results from this study support that leaching of metals from treated wood is driven by rainfall. The concentration and masses of leached metals is dependent on the retention level of the treated wood with higher retention levels resulting in higher concentrations in leachates and a greater mass of metals lost. The results from this study support that the mechanism of leaching is associated with the transport of metals from the interior portions of the wood towards the surface where sudden increases of metals lost were observed at a one week delay from maximum rainfall amounts. Furthermore, we observed that at low retention levels of $\mathrm{CCA}$, the $\mathrm{As}$ and $\mathrm{Cu}$ concentrations were diluted presumably due to a limitation in the amount of metal transported to the surface whereas for high retention levels increases in metal concentrations were observed during the wet season. On the contrary to As and $\mathrm{Cu}$ in CCA, leaching of $\mathrm{Cr}$ from CCA wood and $\mathrm{Cu}$ from ACQ was not subject to dilution effects. Comparing leaching rates observed in the current study with earlier work, which evaluated leaching of new CCA-treated wood under field conditions suggests that weathering can increase leaching rates of As on a percent leached basis (mass leached per mass in wood); however, because the retention of metals in the wood decreases over time, the mass of metals leached would decrease. In spite of the decrease in total mass leached, metals leaching from treated wood are expected to continue over the service life of wood, and the leaching mechanism is expected to change as wood weathers due to loss of $\mathrm{Cr}$ fixation, cracking of wood, and deterioration of the wood fiber.

\section{Recommendations}

Additional experimentation should be conducted to confirm that the observed differences in leaching rates observed between weathered wood used in the current study and new wood used in prior studies is due to the actual weathering process. Such a study should include many different samples of weathered wood along with many samples of new wood evaluated concurrently to quantify the variability due to the weathering process as opposed to variability due to other factors. Since the initiation of the field work associated with this experiment, the wood treatment industry has developed a new micronized formulation for a $\mathrm{Cu}$-based preservative (MCQ), which is believed to leach $\mathrm{Cu}$ at a slower rate relative to the early ACQ formulations as indicated by wood efficacy tests (Freeman and McIntyre, 2008). Of interest would be to evaluate new and weathered micronized $\mathrm{Cu}$ treated wood under natural field conditions to evaluate $\mathrm{Cu}$ leaching rates and to provide a comparison with values published in the literature for other wood preservative formulations.

\section{Supplementary Material}

Refer to Web version on PubMed Central for supplementary material.

\section{Acknowledgments}

Funding for this project was received from the National Institute of Environmental Health Science (NIEHS ES11181). The research team gratefully acknowledges Paul Lopez, Dante Porzilli, Chaithanya Krishna and Dr. Yang Deng for their assistance. We also thank Dr. Michael Kennedy for sharing his data to calculate the CCA-leaching percentage and rate.

\section{References}

Alderman D, Smith R, Araman P. A profile of CCA-treated lumber removed from service in the Southeastern United States decking market. Forest Products Journal 2003;53(1):38-45.

America Wood Protection Association (AWPA). American Wood Protection Association Book of Standards. Granbury, TX: 2008. 
Specification for preservative treatment - Sawn and round timber. Sydney, NSW, Australia: Standards Australia GPO Box 476; 2001. Australian Standard (AS 1604.1-2005). Published by, ISBN 07337 64908

Cooper, PA. Disposal of treated wood removed from service. Proceedings of the Carolinas-Chesapeake Section of the Forest Products Society; Presented at the May 13th, 1993 meeting on Environmental Considerations in the Use of Pressure-Treated Wood Products, Forest Products Society; Madison, WI, USA. 1993.

Dubey, B. Ph.D. Dissertation. Gainesville, FL: University of Florida; 2005. Comparison of Environmental Impacts of Wood Treated with Chromated Copper Arsenate (CCA) and three different Arsenic-Free preservatives.

Dubey B, Townsend T, Solo-Gabriele H, Bitton G. Impact of Surface Water Conditions on Preservative Leaching and Aquatic Toxicity from Treated Wood Products. Environ. Sci. Technol 2007;41(10): 3781-3786. [PubMed: 17547213]

Evans, FG.; Edlund, ML. International Research Group on Wood Preservation. Leaching from field test stakes: results from two different methods of analysis (IRG/WP/50013). Sweden: Stockholm; 1993.

Flemming C, Trevors J. Copper toxicity and chemistry in the environment: a review. Water, Air and Soil Pollution 1989;44:143-158.

Freeman MH, McIntyre CR. A comprehensive review of copper-based wood preservatives with a focus on a new micronized or dispersed copper systems. Forest Product Journal 2008;58(11):6-27.

Jacobi G, Solo-Gabriele H, Dubey B, Townsend T, Shibata T. Evaluation of commercial landscaping mulch for possible contamination from CCA. Waste Management 2007;27(12) 1765-17.

Jambeck J, Townsend T, Solo-Gabriele H. Leaching of chromated copper arsenate (CCA)-treated wood in a simulated monofill and its potential impacts to landfill leachate. Journal of Hazardous Materials 2006;135(1-3):21-31. [PubMed: 16406290]

Jin, L.; Archer, K.; Preston, AF. Proceedings. American Wood Preservers' Association; 1992. Depletion and biodeterioration studies with developmental wood preservative formulations; p. 108-189.

Kennedy, M.; Collins, D. International Research Group on Wood Preservation. Leaching of preservative components from pine decking treated with CCA and copper azole, and interaction with soils (IRG/ WP/01- 0171). Sweden: Stockholm; 2001.

Khan B, Solo-Gabriele H, Dubey B, Townsend T, Cai Y. Arsenic speciation of solvent-extracted leachate from new and weathered CCA-treated wood. Environ. Sci. Technol 2004;38(17):4527-4534. [PubMed: 15461159]

Khan B, Solo-Gabriele H, Townsend T, Cai Y. Release of arsenic to the environment from CCA-treated wood: part I - leaching and speciation during service. Environ 2006a;40(3):988-993.

Khan B, Jambeck J, Solo-Gabriele H, Townsend T, Cai Y. Release of arsenic to the environment from CCA-treated wood. 2. Leaching and speciation during disposal. Environ. Sci. Technol 2006b; 40:994-999. [PubMed: 16509348]

Lebow S, Williams R, Lebow P. Effect of simulated rainfall and weathering on release of preservative elements from CCA treated wood. Environ. Sci. Technol 2003;37(18):4077-4082. [PubMed: 14524438]

McQueen J, Stevens J. Disposal of CCA-treated wood. Forest Products Journal 1998;48(1112):86-90.

Moghaddam AH, Mulligan CN. Leaching of heavy metals from chromated copper arsenate (CCA) treated wood after disposal. Waste Management 2007;28:628-637. [PubMed: 17499985]

Shibata T, Solo-Gabriele HM, Dubey B, Townsend TG, Jacobi GA Jr. Arsenic leaching from mulch made from recycled construction and demolition wood and impacts of iron-oxide colorants. Environ. Sci. Technol 2006;40(16):5102-5107. [PubMed: 16955914]

Shibata T, Solo-Gabriele HM, Fleming LE, Cai Y, Townsend TG. A mass balance approach for evaluating leachable arsenic and chromium from an in-service CCA-treated wood structure. Science of the Total Environment 2007;372(2-3):624-635. [PubMed: 17161449]

Stook K, Dubey B, Ward M, Townsend T, Bitton G, Solo-Gabriele H. An evaluation of the heavy metal toxicity of pressure treated wood leachates with MetPLATE. Bulletin of Environmental Contamination and Toxicology 2004;73(6):987-994. [PubMed: 15674711] 
Stook K, Tolayamat T, Ward M, Dubey B, Townsend T, Solo-Gabriele H, Bitton G. Relative leaching and aquatic toxicity of pressure-treated wood products using batch leaching tests. Environ. Sci. Technol 2005;39(1):155-163. [PubMed: 15667090]

Taylor JL, Cooper PA. Effect of climatic variables on chromated copper arsenate (CCA) leaching during above ground exposure. Holzforschung 2005;59(4):467-472.

Townsend T, Dubey B, Tolaymat T, Solo-Gabriele H. Preservative leaching from weathered CCA-treated wood. Journal of Environmental Management 2005;75:105-113. [PubMed: 15763153]

U.S. Environmental Protection Agency (EPA). Acid digestion of sediments, sludges, and solids (3050B). Washington, DC: U.S. EPA; 1996. Available at: http://www.epa.gov/epaoswer/hazwaste/test/main.htm

Weis P, Weis J. Accumulation of metals in consumers associated with chromated copper arsenate-treated wood panels. Mar. Environ. Res. 1999 1999;48:73-81.

Williams RS, Knaebe MT, Evans JW, Feist WC. Erosion rates of wood during natural weathering. Part III. Effect of exposure angle on erosion rate. Wood Fiber Science 2001;33(1):50-57. 


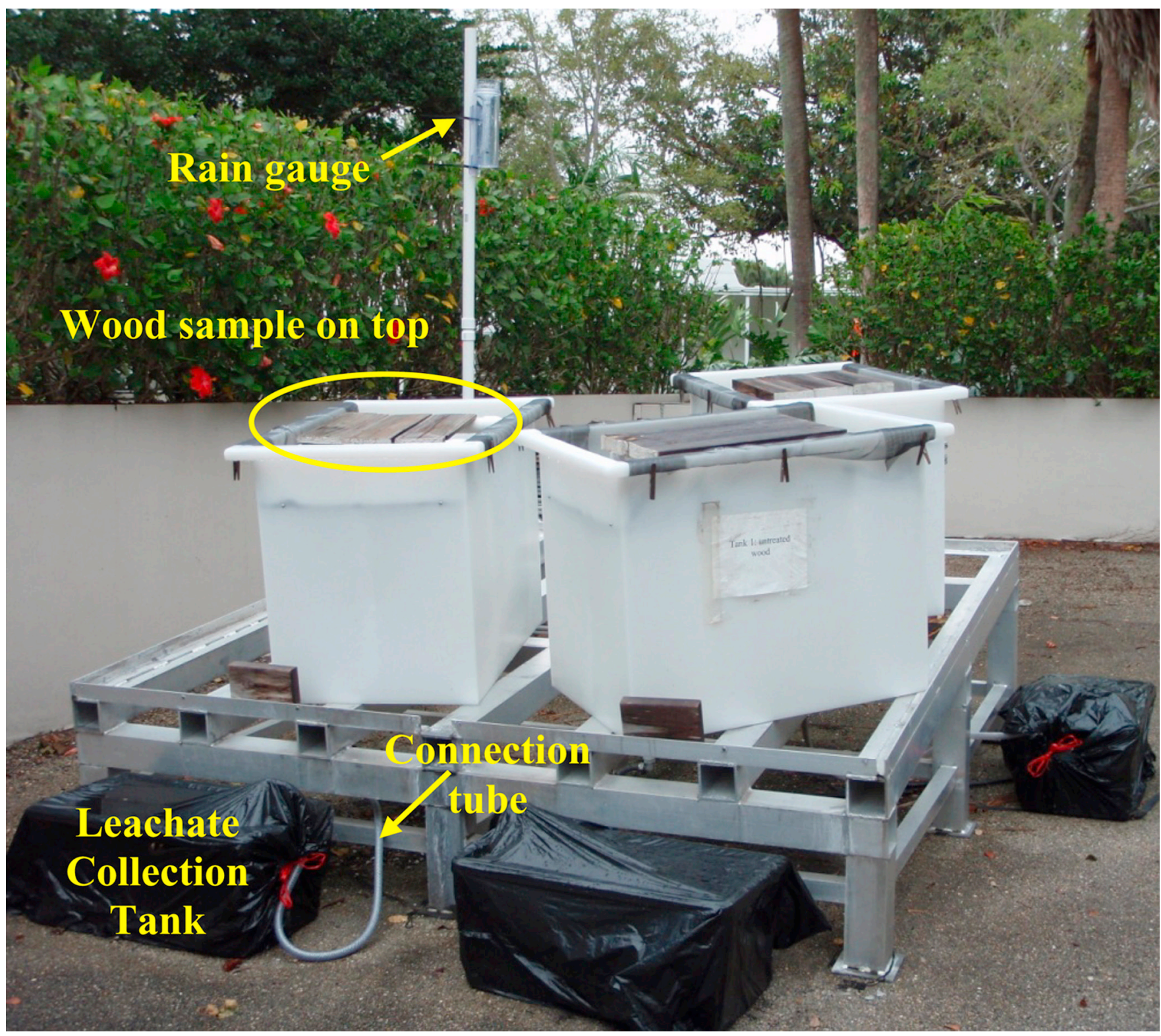

Fig. 1.

The experimental leachate-collection systems. 

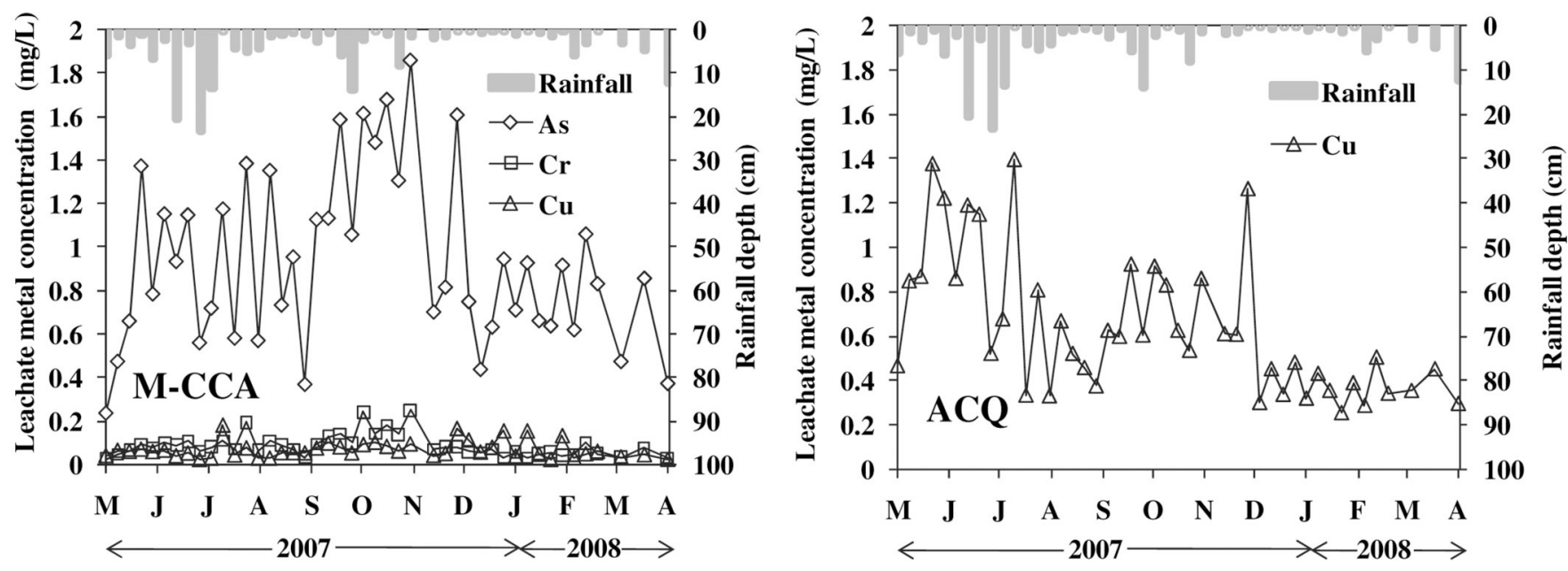

Fig. 2.

Time series plots of rainfall and metals' concentrations in leachates for M-CCA and ACQ treated wood samples. 


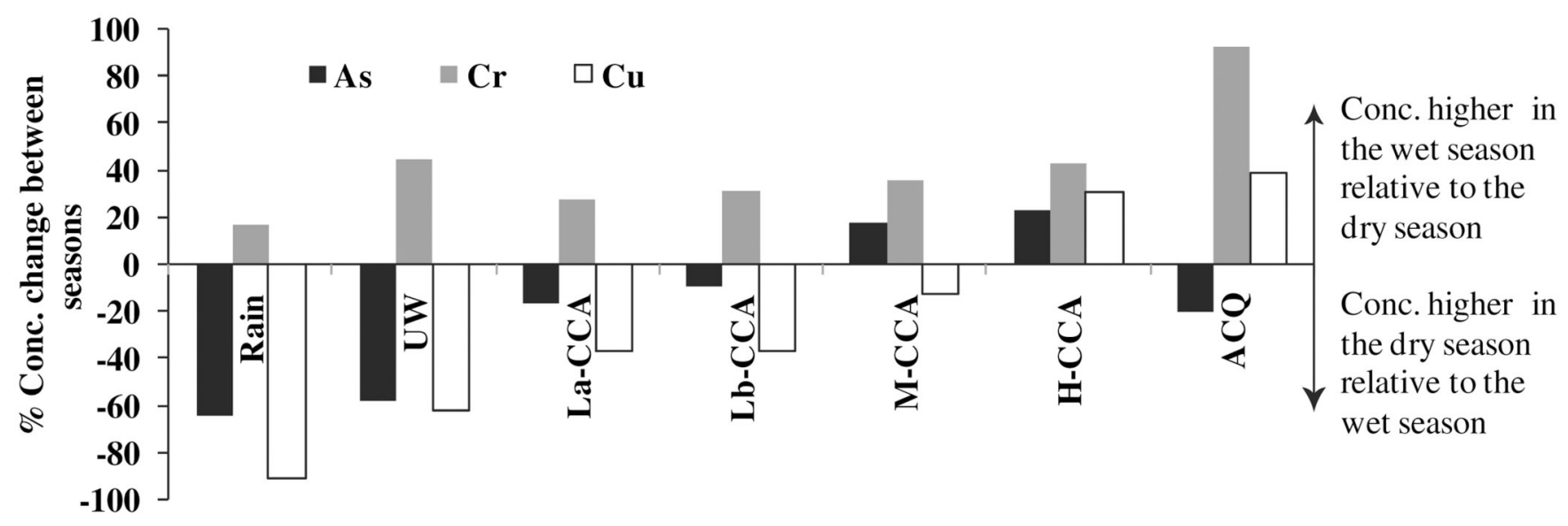

Fig. 3.

Percentage change of average measured concentration of $\mathrm{As}, \mathrm{Cr}$ and $\mathrm{Cu}$ from wet season relative to dry season over the experimental period. Percent change is defined as the average concentration during the wet season minus the average concentration during the dry season divided by the highest seasonal concentration. The ACQ wood sample was low in As and $\mathrm{Cr}$ level, so the high percentage change of $\mathrm{Cr}$ reflects losses of only minute values. The same can be said for $\mathrm{As}$ and $\mathrm{Cu}$ in rain. 


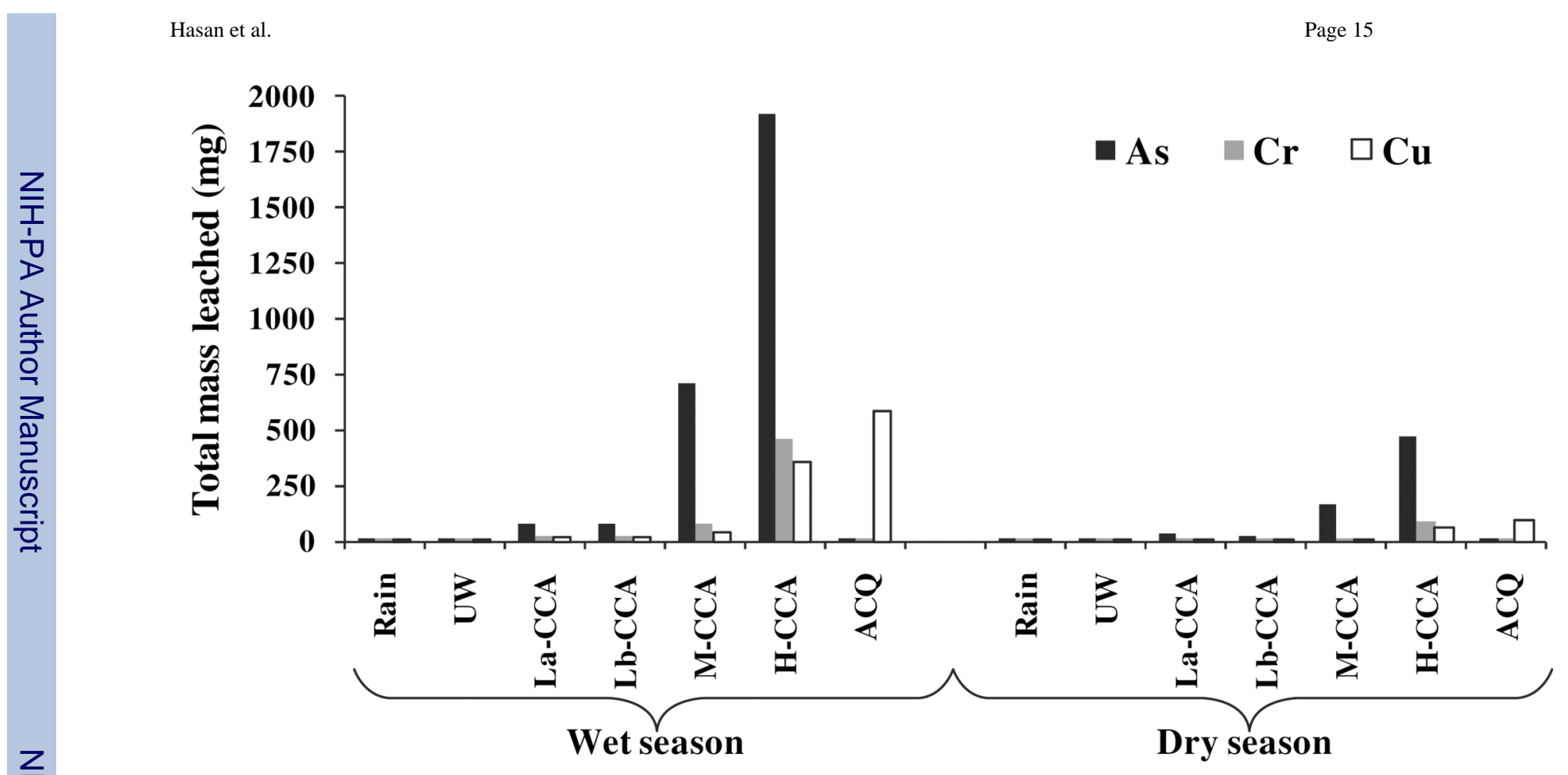

Fig. 4.

Total mass of $\mathrm{As}, \mathrm{Cr}$ and $\mathrm{Cu}$ leached during the wet and dry seasons. 


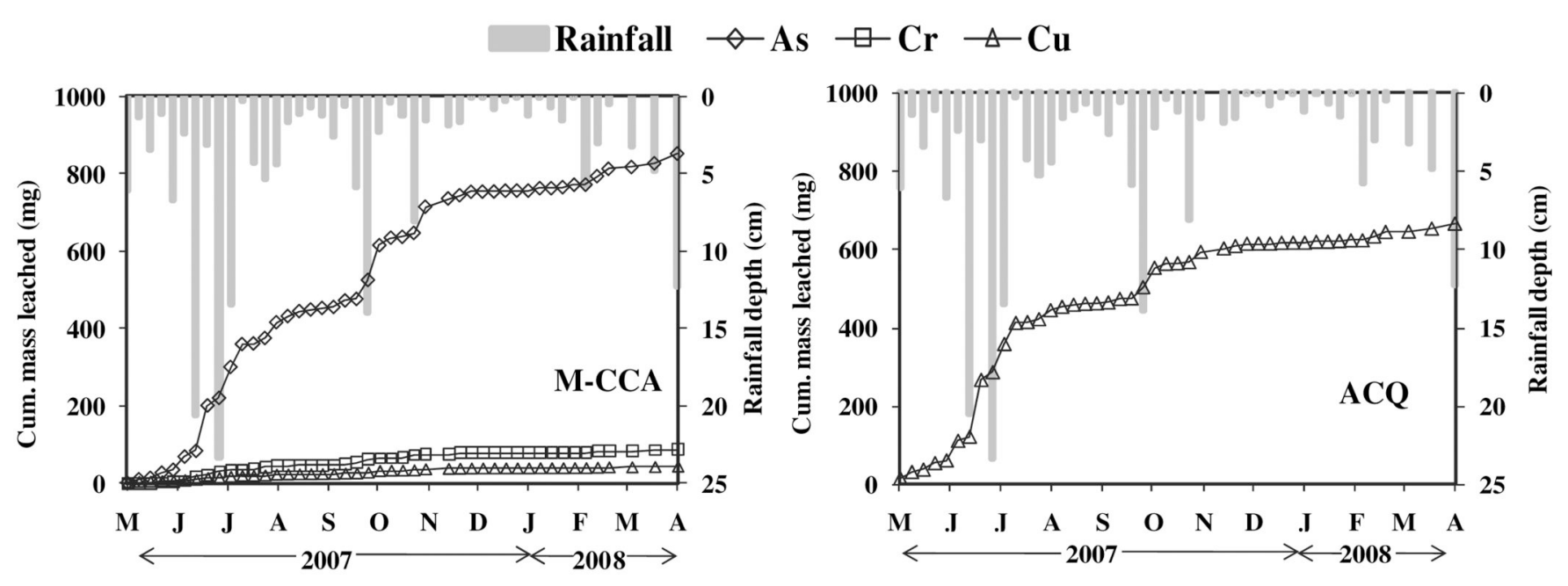

Fig. 5.

Cumulative leaching of metals from wood over the experimental period for M-CCA and ACQ. 


\section{Table 1}

Characteristics of wood samples including number of pieces, dimensions, surface area, and wood volume.

\begin{tabular}{llccc}
\hline Label & $\begin{array}{c}\text { No. of } \\
\text { Pieces/shape }\end{array}$ & $\begin{array}{c}\text { Dimension of } \\
\text { each piece }(\mathbf{c m})\end{array}$ & $\begin{array}{c}\text { Total area } \\
\text { impacted by } \\
\text { rainfall }\left(\mathbf{c m}^{2}\right)\end{array}$ & $\begin{array}{c}\text { Total wood } \\
\text { volume }\left(\mathbf{c m}^{\mathbf{3}}\right)\end{array}$ \\
\hline UW & 2, rectangular & $57 \times 17.8 \times 3.8$ & 2029 & 7711 \\
ACQ & 3, rectangular & $49.5 \times 13.8 \times 3.8$ & 2049 & 7787 \\
La-CCA & 3, rectangular & $49.5 \times 14.1 \times 1.8$ & 2094 & 3769 \\
Lb-CCA & 3, rectangular & $49.5 \times 14.1 \times 1.8$ & 2094 & 3769 \\
M-CCA & 4, rectangular & $8.8 \times 58.5 \times 8.8$ & 2059 & 18121 \\
H-CCA & 1, cylindrical & $\mathrm{L}=74, \mathrm{D}=28.5$ & 2109 & 47227 \\
\hline
\end{tabular}




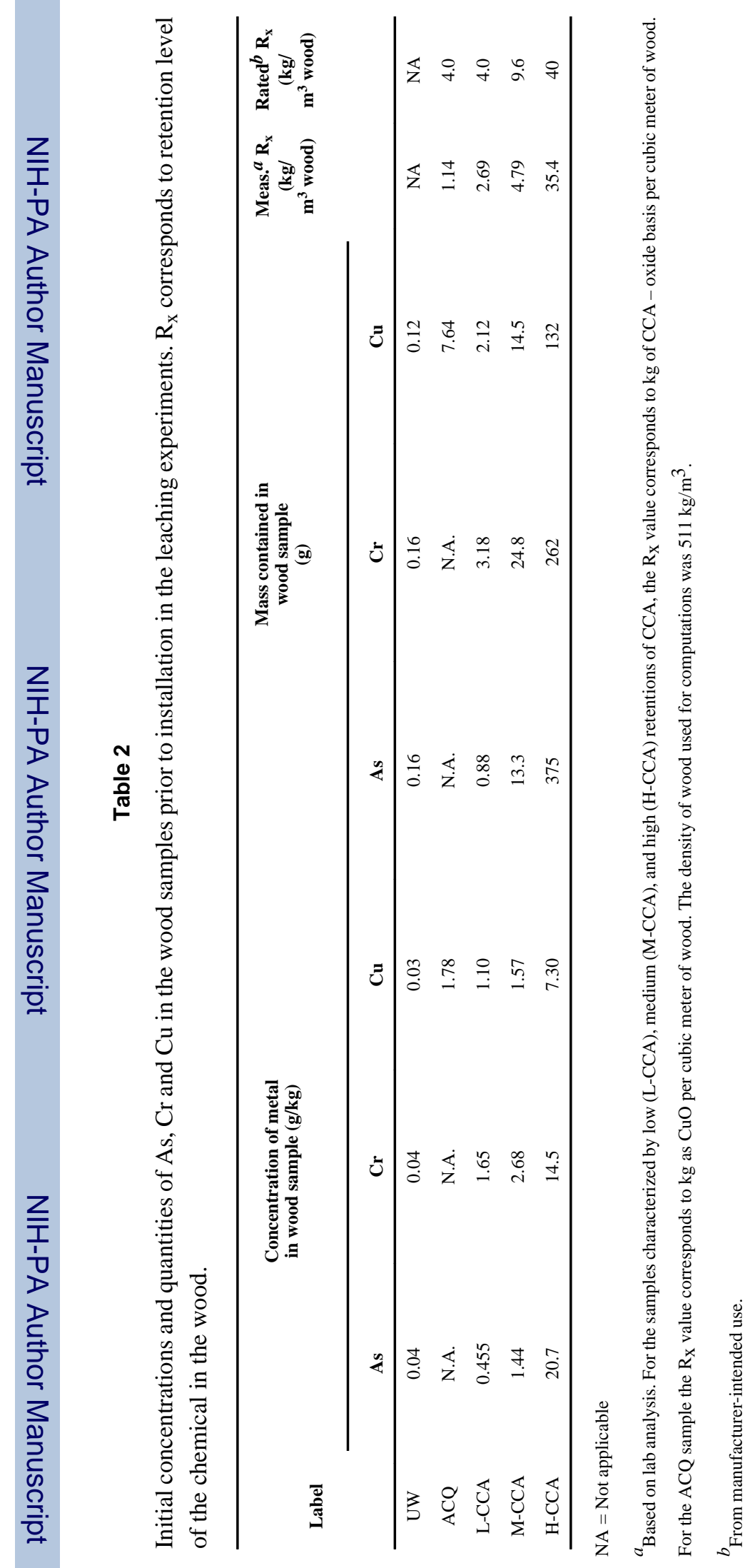




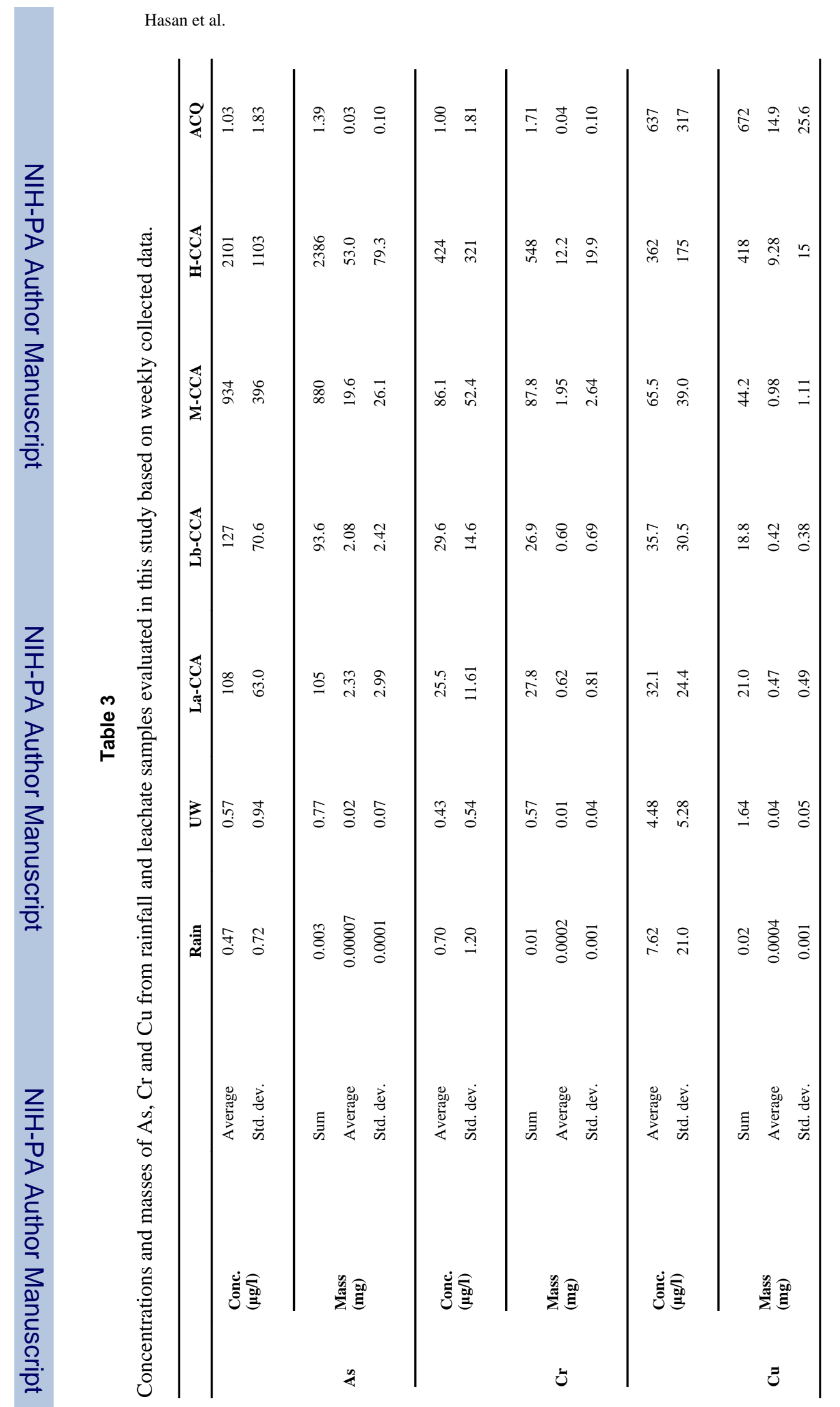




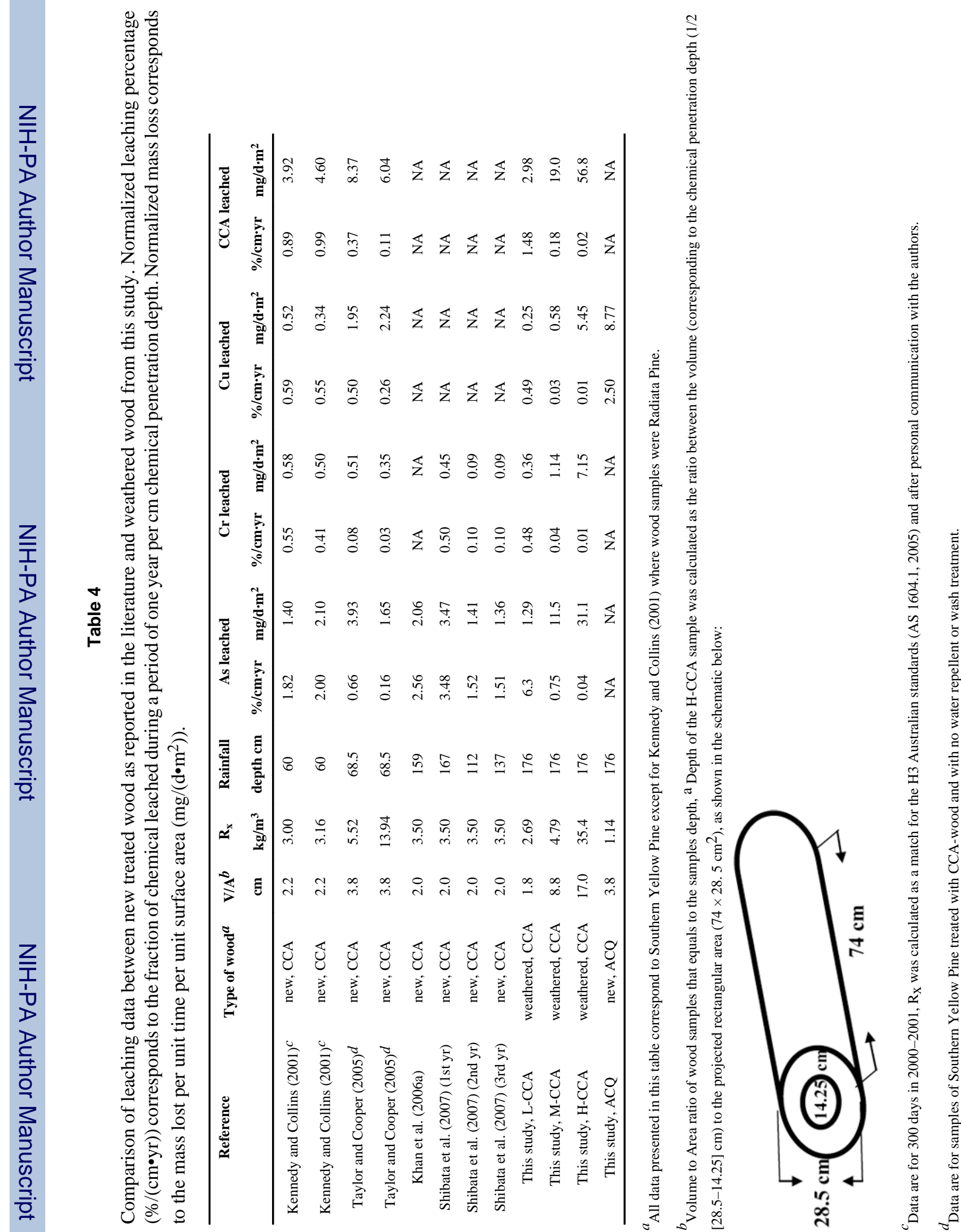

